\title{
GRAMÁTICA Y MARCAS DE IDEOLOGÍA \\ EN EL TRATADO ELEMENTAL DE LA LENGUA CASTELLANA (1915) DE RUFINO BLANCO Y SÁNCHEZ
}

\author{
Alfonso Zamorano Aguilar \\ Universidad de Córdoba ${ }^{1}$
}

\section{Resumen}

El objetivo del presente artículo es analizar las relaciones entre ideología y gramática y, de forma específica, lo que hemos denominado nivel extralingüístico, es decir, la presencia de marcas o índices de ideología social, histórica, cultural, política o filosófica en los textos gramaticales. Para ello, analizamos el Tratado elemental de la lengua castellana (1915) de Rufino Blanco y Sánchez, intelectual relevante en la pedagogía española de principios del siglo xx. La metodología aplicada será la historiografía lingüística interna y externa (Brekle, 1986) y la teoría comunicativa, tal y como ya hemos defendido en otros trabajos de nuestra autoría.

Palabras clave: Ideología, gramática, historiografía lingüística, Rufino Blanco, siglo xx.

\section{GRAMMAR AND IDEOLOGY MARKS IN THE TRATADO ELEMENTAL DE LA LENGUA CASTELLANA (1915) BY RUFINO BLANCO Y SÁNCHEZ}

\begin{abstract}
The aim of this article is to analyse the relationship between ideology and grammar and, specifically, what we have called the extralinguistic level, that is, the presence of social, historical, cultural, political or philosophical ideology marks or indexes in grammatical texts. To this end, we analyse the Tratado elemental de la lengua castellana (1915) by Rufino Blanco y Sánchez, an important intellectual pedagogue in the early 20th

1 Este trabajo se inscribe en el marco del proyecto HisPanAGRAma «Las ideas gramaticales en la América del Pacífico y El Caribe (1800-1950): fuentes, focos, series textuales y canon» [FFI2017-86335-P] del Mineco, Plan Estatal de Investigación Científica y Técnica y de Innovación. IP1: Alfonso Zamorano Aguilar; IP2: Esteban T. Montoro del Arco.
\end{abstract}

Fecha de recepción: 21 de octubre de 2018

Fecha de aceptación: 13 de mayo de 2019 
century in Spain. The applied methodology will be the internal and external linguistic historiography approach (Brekle, 1986) and the communicative theory, as we have already defended in other works of our authorship.

Keywords: Ideology, Grammar, Linguistic Historiography, Rufino Blanco, 20th Century.

\section{Introducción. IdeOlogía y teXtos Lingüísticos: LA GRAMÁtica}

En Calero Vaquera (2010: 32) se pone de relieve la tradición que supone el estudio de la ideología en los textos de corte gramatical, aunque también en los textos lingüísticos en general:

[n]o es una novedad el estudio de las marcas ideológicas en obras de carácter lingüístico, como pueden ser los diccionarios, las gramáticas y, en menor medida, las publicaciones de tema ortográfico.

La propia profesora Calero Vaquera ya había publicado en 2004 (cf. Calero Vaquera, 2004) un trabajo en el que aventuraba la creación de una posible disciplina en la que lo ideológico se unía a lo gramatical: la etnogramática ${ }^{2}$. Y nosotros mismos, en 2013, dedicamos un trabajo a las relaciones entre pensamiento pedagógico y pensamiento gramatical (Zamorano Aguilar, 2013), en el que contrastábamos las ideas de Ezequiel Solana (1863-1931), representante del humanismo espiritualista cristiano, y Manuel Montoliu (1877-1961), que encarna un pensamiento didáctico más «liberal, aunque tradicional y secularizado»(Zamorano Aguilar, 2013: 537).

Así pues, la presencia de pensamiento ideológico se manifiesta como una constante en los textos gramaticales, tal y como demuestran, entre otras, las investigaciones de Calero Vaquera (2010) para textos del siglo Xıx. Y no solo, para el caso del español, en gramáticas peninsulares, sino también en los textos latinoamericanos, como ha ilustrado ampliamente la línea de investigación glotopolítica que ha desarrollado en Argentina la profesora Elvira Narvaja (Narvaja, 2008).

Las gramáticas escolares, además, suelen ser canales idóneos para el despliegue de marcas ideológicas, ya que pretenden «disciplinar sujetos y prácticas» (Narvaja, 2008: 308), de manera que se convierten en recursos habituales asumidos por «el aparato escolar»(Narvaja, 2008: 287) ${ }^{3}$ :

2 Véase nota 5 de este artículo.

3 Conviene anotar, también, a pesar de que no sea el objeto de nuestro análisis, que todo tratado gramatical, de alguna manera, transporta una visión específica (una ideología también) de la lengua que pretende describir, explicar o prescribir. Así, no será lo mismo la visión de la lengua que plasme una gramática académica que la que defienda una gramática de orientación generativa. Del mismo modo, tampoco será comparable dicha visión del código lingüístico en el caso de una gramática escolar o una gramática teórica. En virtud del 
Este recurso didáctico, por el que se establecen correlatos entre el plano lingüístico y el plano sociocultural, permite rastrear datos y elementos del ámbito cultural, ideológico, etc. de una época determinada en obras gramaticales de la tradición (Calero Vaquera, 2010: 37).

\section{FUndAMENTOS TEÓRICOS Y METODOLÓGICOS}

\subsection{Lo extralingüistico en la lengua. Delimitación de nuestros objeto y método de estudio}

En la investigación lingüística el estudio de las relaciones entre el mundo exterior a la lengua y la propia lengua es el objeto de trabajo de varias disciplinas relacionadas. No obstante, y con el fin de fijar adecuadamente el objeto específico de este artículo, conviene que precisemos los siguientes pares dicotómicos: a) lengua y reflexión sobre la lengua; b) perspectiva sincrónica y perspectiva histórica.

En primer lugar, la lengua, como código, puede analizarse en su relación con el mundo extralingüístico (cultural o social) desde una óptica tanto sincrónica como histórica. En este terreno la sociolingüística y la sociología del lenguaje abordan la variación lingüística en función de la organización social de las comunidades en que aquella se desarrolla (Coseriu, 1981: 10; Casado Velarde, 1991: 41); por su parte, la etnolingüística (o antropología lingüística, sin entrar aquí en más precisiones conceptuales ${ }^{4}$ y la etnografía lingüística, ambas desde los planos universal, histórico e individual (Coseriu, 1981), se encargarán, respectivamente, de estudiar «los hechos lingüísticos en cuanto determinados por los 'saberes' acerca de las cosas (cultura)» (Casado Velarde, 1991: 41) y de cómo la cultura es manifestada por el lenguaje y su manifestación en las distintas lenguas. Estas relaciones bidireccionales entre codificación en/de la lengua y lo extralingüístico (social o cultural) no serán el objeto de investigación en este artículo.

En segundo lugar, la reflexión y teorización sobre la lengua son estudiadas por diversas disciplinas que, en líneas generales, podemos condensar en la epistemología lingüística (desde la perspectiva sincrónica) y la historiografía de la lingüística (en virtud de un prisma histórico). En ambos casos se pretende dar cuenta de la valoración, validación, conveniencia, armadura metodológica, etc. de teorías lingüísticas. En este sentido, la presencia de lo extralingüístico (socio-histórico-cultural) se manifiesta de formas diversas y

\footnotetext{
enfoque que pretenda visibilizarse nos encontraremos ante cuestiones teóricas o ante cuestiones socio-histórico-culturales, que podrían, respectivamente, corresponderse con tópicos diversos dentro de lo que denominamos niveles intra y extralingüísticos de la ideología (cf. apartado 2.2 de este artículo).

${ }^{4}$ Cf. los trabajos clásicos y delimitadores de estas disciplinas, entre otros, Terracini (1951), Cardona (1976) y Duranti (2000).
} 
a través de marcas distintas. Aquí se sitúa el objeto de análisis del presente artículo: el estudio de las marcas de lo extralingüístico en datos procedentes de la historiografía de la lingüística, en concreto, de la gramaticografía ${ }^{5}$.

El enfoque historiográfico que defendemos en este trabajo, y que ya hemos adoptado en otras investigaciones, resulta de un marco metodológico doble; por un lado, la historiografía lingüística interna y externa (esta segunda línea resulta aquí esencial por su bondad metodológica a la hora de abordar aspectos no inmanentes al hecho historiográfico), según los planteamientos de Swiggers (1980) y Brekle (1986); por otro, la teoría comunicativa en la formulación clásica de Jakobson (1983).

En consecuencia, partimos de la tesis de que, historiográfica y metodológicamente, resulta relevante interpretar la obra gramatical como un acto comunicativo en el que un emisor (tratadista, gramático o pedagogo) ofrece a un receptor (estudiantes, público general, etc.) un mensaje técnico específico (texto y paratextos de la gramática) a través de un canal concreto (tratado de gramática: manual, epítome, compendio, etc.) con un código o códigos delimitados (gramáticas monolingües, bilingües o multilingües) en el marco de un contexto socio-histórico, político y filosófico también específico (Zamorano Aguilar, 2012).

\subsection{Concepto y niveles de la ideología desde la teoría comunicativa y la gramati- cografía}

El concepto de ideología (como un elemento que se ha atribuido con frecuencia a lo extralingüístico) ha sido abordado desde distintas perspectivas no solo desde el ámbito social sino también desde la óptica lingüística (Van Dijk, 1998). Nuestro punto de vista en la definición del concepto es amplio y categoriza la 'ideología' como los índices o marcas de pensamiento compartido o de creencias diversas, que, en el caso de la gramática, se pueden concretar en dos niveles distintos:

a) Nivel intralingüístico: creencias o representaciones teóricas o de doctrina científica. Se trata del nivel estrictamente metodológico en el que los gramáticos muestran, de forma explícita o encubierta, sus fuentes, su programa teórico y su visión de la disciplina, así como sus propuestas peda-

5 Es preciso señalar que la distinción que hemos establecido entre lengua y reflexión sobre la lengua para relacionar cada uno de sus métodos con el estudio de lo extralingüístico (cómo influye, cómo se interconecta, etc.), tiene su equiparación en disciplinas de nueva creación. A nuestro juicio, este es el criterio que permitiría delimitar y no confundir, por ejemplo, la etnogramática (centrada en la reflexión sobre la lengua, cf. Calero Vaquera, 2004) y la etnosintaxis (centrada en la lengua y cuyo objetivo es el «study of connections between the cultural knowledge, attitudes, and practices of speakers, and the morphosyntactic resources they employ in speech», Enfield, 2002: 3; cf. etiam Wierzbicka, 1979). 
gógicas, con la consiguiente transposición didáctica, si procede, en virtud de los receptores de la obra.

b) Nivel extralingüístico: creencias o representaciones sociales, políticas, filosóficas, religiosas o, en general, histórico-culturales. En este nivel se concreta, a través de marcas de muy diversa índole, todo el pensamiento extralingüístico de los gramáticos. Dicho pensamiento puede condicionar, o no, el nivel intralingüístico. Esta tensión entre ambos niveles será historiográficamente pertinente, de ahí que requiera de investigaciones particulares y de conjunto.

Consideramos, además, que en la investigación historiográfica todas estas marcas de pensamiento compartido se vierten no solo en el texto propiamente dicho, sino también en los paratextos y en las series textuales (Zamorano Aguilar, 2013), con el fin de estudiar la posible evolución de la ideología (desde un punto de vista onomasiológico o semasiológico) a través de la historia.

\subsection{El ejemplo: fuente de ideologías en el nivel extralingüistico}

El ejemplo ha sido una de las unidades privilegiadas de la investigación historiográfica a la hora de justificar la presencia de la ideología (prioritariamente la que hemos señalado como perteneciente al nivel extralingüístico) en los textos gramaticales.

El interés, pues, se ha concentrado en el ejemplo y no en otros tipos textuales, precisamente por el hecho de que la gramática, en nuestra concepción de la obra como acto comunicativo, no siempre tiene una función didáctica ni va dirigida a escolares o aprendices de lengua. El componente ideológico según nuestra doble concepción (cf. apartado 2.2 de este artículo), en cambio, es idéntico con independencia del receptor: ideología teórica o ideología socio-histórico-cultural. La diferencia estribará en el grado de presencia de uno u otro componente ideológico en función de dicho receptor, así como la coherencia o no entre ambos niveles de la ideología, hipótesis que resulta interesante desde el punto de vista historiográfico por su relevancia en la constitución y desarrollo de las ideas lingüísticas en función del eje tiempo.

Así pues, la importancia del ejemplo, desde la óptica historiográfica, ha sido puesta de relieve por numerosos estudiosos. Chevalier (1976) llama la atención sobre la preponderancia en el estudio de las reglas lingüísticas en los textos gramaticales presentes o históricos y sobre la desatención al estudio de los ejemplos. En un sentido parecido se manifiestan Chevillard et al. $(2007: 5)^{6}$.

${ }_{6}$ Estos autores definen así el «ejemplo»: «Nous donc convenus d'appeler, dans un texte grammatical, tout objet linguistique, quelle que soit sa structure, issu de la langue objet: tout 
También Olkhovikov (1985), Fournier (1998), Chierchietti (2010), Cappeau et al. (2010), Gómez Asencio (2016) o Quijada van den Berghe (2017) ponen de relieve la necesidad de estudiar este tipo de microtextos y ponderan, en diversas etapas de la historia gramatical, de tradición hispánica o no, las diferentes funciones y el valor contextual que el ejemplo tiene en el marco de la gramática, como obra de descripción y explicación lingüísticas.

Varias investigaciones convienen en que los ejemplos empleados por los gramáticos pertenecen a dos grandes categorías: a) ejemplos construidos por el tratadista (inventados); b) ejemplos procedentes de obras literarias:

Sin entrar en los detalles, queda claro que los dos tipos de ejemplos, los ejemplos literarios y los ejemplos de expresiones posibles, estriban en teorías lingüísticas distintas. El tipo de ejemplos empleado puede servir, pues, de indicador de tales diversidades (Niederehe, 1994: 414).

Destaca el profesor Niederehe la importancia del ejemplo para la concreción de ideologías («diversidades» en su terminología), a la vez que pondera la función primordial que la literatura cumple en la construcción de estos fragmentos textuales. Se opone, en este sentido, a la postura de De Kock (1990: 42), para quien:

[c]uatro siglos de literatura, en prosa y en verso, de usos y libertades dispares, constituyen un marco demasiado poco homogéneo para que, didácticamente, puedan servir de pauta en el aprendizaje de la lengua.

Como mostraremos en seguida a través del Tratado de Rufino Blanco y Sánchez (1915), el gramático hace un uso destacado tanto de la literatura como de los ejemplos «de expresiones posibles» (Niederehe, 1994: 414) o «discursos imaginados y atribuidos a personajes de ficción», como los denomina Chierchietti (2010: 57), quien entiende, frente a De Kock (1990), la literatura «como una importante fuente de información, sobre todo para aportar ejemplos ilustrativos de cierta elaboración retórica» (Chierchietti, 2010: 60).

Las funciones y las formas que adoptan los ejemplos en las gramáticas también han sido objeto de investigaciones en el campo de la historiografía (Chevillard et al., 2007; Kistereva, 2014-2015; Gómez Asencio, 2016; Quijada van den Berghe, 2017; Escudero Paniagua, 2017); en concreto, el siglo xIx, como precedente del Tratado de Blanco y Sánchez, ha recibido la notable

\footnotetext{
fragment de la langue objet inséré dans le discours grammatical» (Chevillard et al., 2007: 6). Kistereva (2014-2015) y Chierchietti (2010) acogen esta definición del ejemplo, aunque la primera investigadora aporta una definición propia: «Tout fragment issu de la langue objet du discours grammatical concernant la langue-objet, extrait d'un ensemble d'usages, mis en avant pour observer un ensemble de faits similaires et invoqué a des fins de démonstration et de preuve» (apud Chierchietti, 2010: 11).
} 
atención de la crítica (Chevalier, 1976; Lliteras Poncel, 2001). En Kistereva (2014-2015), siguiendo en parte a Chevillard et al. (2007), se indican algunas de las funciones principales de los ejemplos en los textos gramaticales: función ilustrativa o filológica, demostrativa, predictiva, enciclopédica, didáctica $^{7}$ o ideológica. A estas funciones, sin duda, también convendría añadir la argumentativa. En nuestro Tratado, Blanco parece formalizar todas estas funciones tanto en los ejemplos como en los ejercicios, aunque en esta investigación nos interesa destacar la perspectiva didáctico-pedagógica y el objetivo ideológico, tanto teórico como socio-histórico-cultural. De hecho, Kistereva (2014-2015), haciendo suyas las palabras de Wooldrigde (1995), considera que ambas funciones (didáctica e ideológica) se encuentran estrechamente unidas, en la línea que hemos apuntado con Narvaja (2008).

3. El Nivel SOcio-histórico-GUltural de la ideología EN EL TRATADO ELEMENTAL DE LA LENGUA CASTELLANA (1915). Marcas ideOLóGigas EN EL MENSAJE GRAMATICAL

\subsection{Los ejemplos en la teoría gramatical}

El estudio de los «fragmentos textuales» que el gramático emplea para ilustrar, aplicar, reforzar, contravenir, ampliar, enseñar, ideologizar, etc. una categoría o teoría lingüística resulta de gran interés en la investigación etnogramatical, en este caso, desde un punto de vista historiográfico (cf. apartados 1 y 2 de este artículo). Estos «fragmentos textuales» se hallan insertos en la microestructura de la gramática y no solo tienen formas, sino también funciones diversas en la totalidad de la obra, según ya hemos destacado supra. El gramático los emplea como índices de ideología teórica o como índices de ideología socio-histórico-cultural (niveles intra y extralingüísticos, respectivamente, de nuestra concepción de la ideología). En palabras de Calero Vaquera (2004: 323-324):

Creemos que, al igual que sucede con el lexicógrafo, el autor de un tratado gramatical es hijo de su tiempo, de su cultura y de su sociedad y se encuentra, por tanto, sometido a unos modelos y estereotipos socio-culturales que en ocasiones (de forma consciente o inconsciente) emergen y quedan plasmados en su producción científica.

Nos estamos refiriendo a un amplio conjunto de microtextos que abarca desde ejemplos para funciones variadas durante el proceso de explicación

7 Sobre la función didáctica se indica que «concerne l'aspect instructif des examples. L'exemplum médiéval est la source principale de ce genre dans les premiers traités grammaticaux: les exemples qui offrent des modèles de comportement et de la morale constituent le type des exemples éducatifs ou édifiants» (Kistereva, 2014-2015: 24). 
de una teoría gramatical específica, hasta ejercicios de aplicación, que pueden ser fragmentos para el reconocimiento de categorías, fragmentos para la explicación léxico-semántica, fragmentos para completar con unidades específicas - por razones morfológicas, ortográficas o léxicas-, fragmentos para la lectura, etc.

Sin ánimo de ser exhaustivo en este aspecto, pues no es el objetivo específico de este trabajo, podemos establecer la siguiente tipología y características de estos «fragmentos textuales» que son objeto de ideologías diversas en el seno de las gramáticas en general y del Tratado de Blanco en particular:

1. Se trata de unidades inventadas o extraídas de la literatura.

2. Son indicios o marcas de ideología teórica, de ideología socio-histórico-cultural o de ideología mixta de las dos anteriores.

3. Se trata de unidades oracionales o textuales, completas o incompletas (suele dejarse un hueco o un guion para ser completado), de unidades sintagmáticas o de unidades léxicas o listas de palabras (Esteba Ramos, 2005).

4. Generalmente, aparecen en gramáticas de corte pedagógico o escolar con una función didáctica prioritaria y funciones secundarias diversas: ideológica o de aplicación (ilustración, refuerzo, contraargumento, prescripción, etc.) de la teoría gramatical.

5. Desde el punto de vista tipológico podemos distinguir:

a) Ejemplos.

b) Ejercicios:

b1) Ejercicios de aplicación.

b2) Ejercicios de composición.

b3) Ejercicios de lectura.

En todos los grandes tipos indicados los fragmentos son siempre índices de ideología teórica, socio-histórico-cultural o mixta. No obstante, suelen ser prioritariamente marcas de ideología en el nivel extralingüístico.

Veamos, a continuación, todos estos aspectos reseñados en el Tratado de Blanco. Centraremos nuestra atención, de manera conjunta, en los ejemplos y en los ejercicios de aplicación, según la clasificación que acabamos de exponer. En cuanto a los ejercicios de aplicación, dada su riqueza y variedad, solo analizaremos aquellos que son comparables (estructuralmente hablando) a los ejemplos, es decir, oraciones o textos completos, omitiendo, pues, tanto unidades sintagmáticas como listas léxicas. 


\subsection{Análisis del corpus: los ejemplos en el Tratado de Blanco y Sánchez}

Hemos localizado y constituido un corpus de 347 fragmentos textuales, que arrojan los siguientes datos de interés historiográfico:

Tabla 1. Temática de los ejemplos y ejercicios. Ocurrencias totales

\begin{tabular}{|c|c|c|c|c|c|c|c|}
\hline Naif & Moralista & Histórica & Geográfica & Literaria & Social & Religiosa & Meta \\
\hline 109 & 109 & 25 & 3 & 30 & 14 & 52 & 5 \\
\hline $31,4 \%$ & $31,4 \%$ & $7,2 \%$ & $0,86 \%$ & $8,64 \%$ & $4,03 \%$ & $14,98 \%$ & $1,44 \%$ \\
\hline
\end{tabular}

En Zamorano Aguilar (2013) contrastábamos, como señalamos al inicio de este trabajo, la temática de los ejemplos en Ezequiel Solana (representante, como Blanco y Sánchez, de la pedagogía humanista católica de principios del siglo xx) y Manuel Montoliu (a quien podemos adscribir a la neutralidad liberal) y, en el caso del gramático castellano-leonés, en la línea que acabamos de presentar en la tabla 1 para Blanco, los ejemplos contenían, de forma significativa, ideología moralista y religiosa, junto con fragmentos que calificamos de «naif» por tratarse de unidades que hacían referencia al campo, las flores, los juegos, etc., sin marca ideológica definida.

En el caso de Blanco y Sánchez observamos una profusión de fragmentos textuales, tanto en los ejemplos de la teoría gramatical como en los ejercicios, con contenido moralista y religioso (total: 46,38\%), fiel reflejo de la ideología conservadora en materia político-social de nuestro autor. Ejemplos de la doctrina moralista son: Es preferible la pobreza a la deshonra, Más vale obrar bien, que hablar seriamente o El padre, la madre y las hijas son buenos. Por lo que respecta a los fragmentos de temática religiosa: En la cruz murió Jesucristo, El Papa es la cabeza visible de la Iglesia o Dios es amor. En numerosas ocurrencias el contenido religioso y el moralista se encuentran unidos, por ejemplo, en El hombre de ahora no es tal como Dios lo crió, sino que es un hombre degenerado. Los estereotipos sociales son un reflejo en Blanco de su moralismo cristiano y conservador, como se percibe en este ejemplo: Un hijo bueno es el regocijo de su padre; pero un hijo insensato es la tristeza de su madre.

El bloque de contenido naif es notable también entre los ejemplos y ejercicios utilizados por Blanco para formalizar sus teorías gramaticales. Se trata de fragmentos cuyo contenido ideológico (desde un punto de vista socio-histórico-cultural) está neutralizado, con lo que se potencia la ideología teórica del autor: La hiena, el tigre y el león son feroces (en el capítulo de la sílaba), El piano, el arpa y la guitarra son instrumentos de cuerda (para aplicar la teoría sobre el número en los sustantivos) o La hormiga se provee de alimento durante el verano recogiendo su comida en tiempo de siega (inserto en el capítulo 
dedicado a la ortografía). Entre los ejemplos de contenido naif, finalmente, encontramos una tipología poco frecuente en Blanco, esto es, los anti-ejemplos, que sirven al autor para defender una determinada regla o principio gramatical: He visto un edificio, cuyo edificio era de arquitectura árabe o La vi y la hablé. Esta idea que acabamos de defender resulta de interés desde el punto de vista de la historiografía de la lingüística, ya que nos permite establecer una primera conclusión con relación a los dos niveles de la ideología con los que trabajamos y su concreción en los ejemplos: cuando se focaliza el interés del gramático en el nivel intralingüístico de la ideología (teoría), se neutraliza el nivel extralingüístico de la ideología, lo que suele suceder en la elección de ejemplos del tipo naif (conclusión 1).

El cuarto bloque de ejemplos por orden de frecuencia es aquel de temática literaria. Encontramos dos tipos de fragmentos:

a) Citas procedentes de la literatura: ¡Cuán pobres y cuán ciegos, ay, nos dejas! (fray Luis de León) u ¡Oh Virgen del Recuerdo dolorida! (Julio Alarcón).

b) Textos metaliterarios que incluyen referencias a obras o autores: Quevedo murió en Villanueva de los infantes, Cervantes nació en Alcalá de Henares o Calderón de la Barca vivió en el siglo XVII.

Son mucho más numerosos los fragmentos elaborados por Blanco que los extraídos de las obras literarias. Con esta dicotomía en los ejemplos de temática literaria, podemos establecer dos conclusiones para las relaciones entre niveles de la ideología según nuestro planteamiento teórico: cuando el gramático desea focalizar su interés en el nivel intralingüístico de la ideología, es decir, en la teoría, suele emplear ejemplos inventados y, consecuentemente, se neutraliza el nivel extralingüístico de la ideología (conclusión 2); en cambio, cuando el gramático utiliza ejemplos extraídos de la literatura, suele producirse una neutralización del nivel intralingüístico de la ideología y, por tanto, presta más atención a la visualización de contenido ideológico en el nivel extralingüístico (conclusión 3).

Sin embargo, la literatura en Blanco se emplea, sobre todo, en los ejercicios para la lectura. El recurso a los autores de la literatura del Siglo de Oro español es bastante evidente y pone de relieve un canon privilegiado frente a otras etapas de la literatura hispánica. Conviene destacar que uno de los libros que más utiliza Blanco para extraer citas como ejemplificación de la teoría lingüística es la Biblia. Así, como muestra, en el capítulo del análisis gramatical incluye, sin indicar la referencia, el fragmento En tus manos encomiendo mi espíritu, que se localiza en Lucas, 23:46. Esta elección textual resulta ser perfectamente coherente con la ideología pedagógica de tipo católico que Blanco defiende en su programa didáctico. 
Los fragmentos de temática social, geográfica o histórica constituyen, en bloque, un volumen reducido (12,09\%). Sin embargo, son una fotografía ideológica de la España de principios del siglo xx:

a) De contenido social: La cantárida es un insecto útil. Este insecto coleóptero fue utilizado como vesicante hasta principios del siglo xx. En los ejemplos El autor, el tipógrafo y el encuadernador intervienen en la producción de los libros y El cerrajero, el herrero, el hojalatero y el fundidor trabajan los metales se dejan entrever aspectos político-económicos de la sociedad y la vida laboral de la España de 1915. Igual ocurre con El buey es un animal muy útil, donde la descripción del buey permite extraer información relativa al trabajo en el campo y su valoración y preeminencia en una España donde la economía era, fundamentalmente, de corte agrario y ganadero.

b) De temática geográfica: El Ebro nace en Fontibre, Llovizna por Occidente y Son célebres las minas de azogue de Almadén (Ciudad Real).

c) De instrucción histórica: Fernando el Santo conquistó Sevilla, Cristóbal Colón descubrió América, Gran estadista fue el Cardenal Cisneros, Granada fue rendida por los Reyes Católicos, etc. La elección de los personajes históricos es sintomática de una ideología subliminalmente impuesta, en este caso, claramente nacionalista y acorde con el clima político, social, religioso, etc. en que Blanco se halla inmerso.

Finalmente, hemos señalado en la tabla 1 la presencia de un contenido que hemos denominado «meta» y que hace referencia a ejemplos/ejercicios de metaconocimiento, es decir, son ejemplos o ejercicios para practicar algún contenido gramatical pero que llevan inserto un contenido específico de lingüística o de otras materias: Hipérbole significa exageración o Hipólito quiere decir caballo de piedra (como ejemplos dentro del bloque de la cantidad silábica) o Un polígono de siete lados se llama heptágono. Se trata de un tipo de ejemplos poco frecuente en la época, lo que permite deducir un nuevo criterio en Blanco con relación a las conexiones entre los dos niveles de la ideología: cuando el gramático pretende focalizar la atención del estudiantado en la teoría (nivel intralingüístico de la ideología), acude al empleo de ejemplos meta, que conlleva, de forma relacionada, una neutralización de los contenidos ideológicos en el nivel extralingüístico (conclusión 4).

\subsection{Las explicaciones de la teoría gramatical y los temas para la composición}

Para la explicación gramatical de la ortología y la pronunciación Blanco propone este ejercicio: «Cuéntense las letras vocales y las consonantes que hay en cada una de estas palabras: Dios, Jesús, María, José, Fe, Esperanza, Caridad, Prudencia, Justicia, Fortaleza, Templanza» (Blanco, 1915: 51). El adoctrinamiento religioso y la ideología cristiana están presentes en la selec- 
ción de estas unidades léxicas para practicar un contenido gramatical que no guarda relación, obviamente, con el significado léxico (e ideológico) de las unidades seleccionadas.

La instrucción moralizante, el estereotipo social y el contenido nacionalista y religioso de la ideología de Blanco se plasman también en ejercicios de composición como el siguiente, dedicado a los vestidos:

\section{EJERCICIO DE COMPOSICIÓN \\ Los vestidos \\ Explíquese este punto con arreglo al siguiente}

\section{Cuestionario}

Principales prendas de vestir.

Descripción de las más importantes de las que cada uno use y tejidos de que se hacen.

Prendas de vestir características de militares y eclesiásticos.

Condiciones que ha de tener el vestido respecto de su clase y precio.

Condiciones higiénicas de los vestidos.

Aseo del vestido (Blanco, 1915: 128; negrita en el original).

El mismo sentido doctrinal se observa en otro ejercicio de composición, en este caso sobre las bebidas, en el cual dos de las ideas del cuestionario son: «Repugnancia de la embriaguez. Necesidad de ser sobrios y ordenados en el uso del vino cuando este sea necesario por prescripción médica» (Blanco, 1915: 172). La defensa de una moral conservadora y de recta actitud se inculca de forma subliminal en la creación de estos ejercicios, teniendo en cuenta, además, el receptor de la obra: bachilleres y alumnado de las Escuelas Normales.

Finalmente, los modismos y paremias (tanto en español como en expresiones latinas: El hábito no hace al monje o ad maiorem Dei gloriam) se constituyen como un formato muy adecuado, según se desprende del uso que hace Blanco, para la expresión de la ideología socio-histórico-cultural. Nos hallamos ante unidades lingüísticas que son receptoras de contenido tradicional de hondas raíces en la cultura general y, en este caso concreto, en la cultura española.

\subsection{Canon literario (lecturas)}

La aplicación de la teoría del canon en historiografía ha resultado ser muy fructífera en metodología y minuciosidad de resultados (Zamorano Aguilar, 2010; Quijada van den Berghe, 2012). En el caso del nivel intralingüístico la teoría del canon se circunscribe al análisis de las fuentes gramaticales o lingüísticas empleadas por el autor investigado (Zamorano Aguilar, 2017). Por lo que respecta al nivel extralingüístico, el estudio canónico 
debemos focalizarlo en el empleo de autoridades literarias como formalización y ejemplificación de las ideas teóricas expuestas (Quijada van den Berghe, 2008).

En el Tratado de Blanco de 1915 localizamos 64 referencias a autores u obras de la literatura universal, aunque, en su mayoría, de las letras españolas. Estas 64 referencias se concretan en 46 autores/obras, pues varios son recurrentes en la gramática investigada.

Junto a textos de corte teórico sobre la literatura (por ejemplo, Caroline Vanhove Talma y sus Reflexiones sobre el arte teatral de 1879), la distribución por frecuencia porcentual de las lecturas (canon literario) que se aprecia en Blanco sería:

Tabla 2. Canon literario. Unidades más frecuentes

\begin{tabular}{|c|c|c|c|c|c|}
\hline Unidad canónica & $N .^{o}$ & $\%$ & Época (siglo) & $T e m a^{8}$ & $\begin{array}{l}\text { Género } \\
\text { literario }\end{array}$ \\
\hline Cervantes & 5 & 7,81 & XVII & $\begin{array}{l}\text { Mor } \\
\text { Gen } \\
\text { Gen } \\
\text { Am } \\
\text { Co }\end{array}$ & $\begin{array}{l}\text { Prosa } \\
\text { Prosa } \\
\text { Prosa } \\
\text { Prosa } \\
\text { Prosa }\end{array}$ \\
\hline Fray Luis de Granada & 3 & 4,68 & XVI & $\begin{array}{l}\mathrm{R} \\
\text { R-Mor } \\
\mathrm{R}\end{array}$ & $\begin{array}{l}\text { Prosa } \\
\text { Prosa } \\
\text { Prosa }\end{array}$ \\
\hline Gonzalo de Berceo & 3 & 4,68 & XIII & $\begin{array}{l}\mathrm{R} \\
\mathrm{R} \\
\mathrm{R}\end{array}$ & $\begin{array}{l}\text { Poesía } \\
\text { Poesía } \\
\text { Poesía }\end{array}$ \\
\hline Zorrilla & 3 & 4,68 & XIX & $\begin{array}{l}\mathrm{R} \\
\text { Gen } \\
\text { Gen }\end{array}$ & $\begin{array}{l}\text { Poesía } \\
\text { Poesía } \\
\text { Poesía }\end{array}$ \\
\hline Fray Luis de León & 3 & 4,68 & XVI & $\begin{array}{l}\mathrm{R} \\
\mathrm{R} \\
\text { Mor-R } \\
\end{array}$ & $\begin{array}{l}\text { Poesía } \\
\text { Poesía } \\
\text { Prosa } \\
\end{array}$ \\
\hline Quintana & 3 & 4,68 & XVIII-XIX & $\begin{array}{l}\text { Gen } \\
\text { Gen } \\
\text { Gen }\end{array}$ & $\begin{array}{l}\text { Poesía } \\
\text { Poesía } \\
\text { Poesía }\end{array}$ \\
\hline
\end{tabular}

8 Las abreviaciones utilizadas hacen referencia a una temática: Gen: generalista; Mor: moralista; Co: costumbrista; Bu: bucólica; R: religiosa; Am: amorosa; Naif: naif; Fo: folklórica; Mit: mitológica; Varia: varia. 
Tabla 2. Canon literario. Unidades más frecuentes (cont.)

\begin{tabular}{|c|c|c|c|c|c|}
\hline Unidad canónica & $N .^{o}$ & $\%$ & Época (siglo) & Tema & $\begin{array}{l}\text { Género } \\
\text { literario }\end{array}$ \\
\hline Lope de Vega & 2 & 3,12 & XVII & $\begin{array}{l}\text { Gen } \\
\text { Gen }\end{array}$ & $\begin{array}{l}\text { Teatro } \\
\text { Teatro }\end{array}$ \\
\hline Quevedo & 2 & 3,12 & XVII & $\begin{array}{l}\text { Co } \\
\text { Co }\end{array}$ & $\begin{array}{l}\text { Prosa } \\
\text { Prosa }\end{array}$ \\
\hline Gaspar Núñez de Arce & 2 & 3,12 & XIx & $\begin{array}{l}\text { Gen } \\
\text { Mor }\end{array}$ & $\begin{array}{l}\text { Poesía } \\
\text { Poesía }\end{array}$ \\
\hline Juana Inés de la Cruz & 2 & 3,12 & XVII & $\begin{array}{l}\text { Am-R } \\
\mathrm{R}\end{array}$ & $\begin{array}{l}\text { Poesía } \\
\text { Poesía }\end{array}$ \\
\hline Bibliotecas de autores & 1 & 1,56 & Varia & Varia & Varia \\
\hline Torres Naharro & 1 & 1,56 & XV-XVI & Co & Teatro \\
\hline Calila e Dymna & 1 & 1,56 & XIII & Mor & Prosa \\
\hline Cecilia Böhl de Faber & 1 & 1,56 & XIX & Co & Prosa \\
\hline José María de Pereda & 1 & 1,56 & XIX & Mor & Prosa \\
\hline Concepción Saiz & 1 & 1,56 & XIX-Xx & Gen & Prosa \\
\hline Juan Muñoz y Pabón & 1 & 1,56 & XIX-XX & Co & Prosa \\
\hline Mariano de Cavia & 1 & 1,56 & XIX-Xx & $\mathrm{R}$ & Prosa \\
\hline Blasco de Garay & 1 & 1,56 & $\mathrm{XVI}$ & Co & Prosa \\
\hline Antologías poéticas & 1 & 1,56 & Varia & Varia & Poesía \\
\hline Romance morisco & 1 & 1,56 & s.f. & Gen & Poesía \\
\hline Adelardo López de Ayala & 1 & 1,56 & XIx & Gen & Poesía \\
\hline Antonio de Trueba & 1 & 1,56 & XIX & $\mathrm{R}$ & Poesía \\
\hline Antonio García Gutiérrez & 1 & 1,56 & XIX & Mit & Poesía \\
\hline Florilegio de poesía s. XIx & 1 & 1,56 & XIX & Varia & Poesía \\
\hline Francisco Cea & 1 & 1,56 & XIX & $\mathrm{R}$ & Poesía \\
\hline José María Gabriel y Galán & 1 & 1,56 & $\mathrm{XIX}$ & R-Fo & Poesía \\
\hline José Selgas & 1 & 1,56 & XIX & $\mathrm{R}$ & Poesía \\
\hline Juan Arolas & 1 & 1,56 & XIX & Gen & Poesía \\
\hline Ventura de la Vega & 1 & 1,56 & XIX & $\mathrm{R}$ & Poesía \\
\hline Blanca de los Ríos de Lampérez & 1 & 1,56 & XIX-Xx & Am & Poesía \\
\hline Vicente Medina & 1 & 1,56 & XIX-XX & Co & Poesía \\
\hline Jorge Manrique & 1 & 1,56 & $\mathrm{xV}$ & Gen & Poesía \\
\hline Juan de Mena & 1 & 1,56 & $\mathrm{XV}$ & Gen & Poesía \\
\hline Garcilaso de la Vega & 1 & 1,56 & $\mathrm{XVI}$ & $\mathrm{Bu}$ & Poesía \\
\hline
\end{tabular}


Tabla 2. Canon literario. Unidades más frecuentes (cont.)

\begin{tabular}{|l|c|c|c|l|l|}
\hline \multicolumn{1}{|c|}{ Unidad canónica } & $N^{\circ}$ & $\%$ & Época (siglo) & \multicolumn{1}{|c|}{ Tema } & \multicolumn{1}{c|}{$\begin{array}{c}\text { Género } \\
\text { literario }\end{array}$} \\
\hline Gutierre de Cetina & 1 & 1,56 & XVI & Am-Naif & Poesía \\
\hline Santa Teresa de Jesús & 1 & 1,56 & XVI & $\mathrm{R}$ & Poesía \\
\hline Calderón de la Barca & 1 & 1,56 & XVII & Bu & Poesía \\
\hline Góngora & 1 & 1,56 & XVII & Gen & Poesía \\
\hline Alberto Lista & 1 & 1,56 & XVIII-XIX & Gen & Poesía \\
\hline Juan Meléndez Valdés & 1 & 1,56 & XVIII-XIx & R & Poesía \\
\hline Andrés Fernández de Andrada & 1 & 1,56 & XVI-XVII & Am & Poesía \\
\hline Bernardo de Balbuena & 1 & 1,56 & XVI-XVII & R & Poesía \\
\hline Francisco de Rioja & 1 & 1,56 & XVI-XVII & Gen & Poesía \\
\hline Jáuregui & 1 & 1,56 & XVI-XVII & Gen & Poesía \\
\hline Luis Martín & 1 & 1,56 & XVI-XVII & Gen & Poesía \\
\hline
\end{tabular}

El análisis del canon literario empleado por Blanco en su Tratado arroja los siguientes datos de interés para el estudio de la ideología socio-históricocultural que nuestro gramático vierte en su obra:

Tabla 3. Canon literario según criterios: época, temática y género

\begin{tabular}{|c|c|c|c|c|c|}
\hline \multicolumn{2}{|c|}{ Según época del canon } & \multicolumn{2}{|c|}{ Según temática del texto } & \multicolumn{2}{|c|}{ Según género del texto } \\
\hline XIX & 13 & Generalista & 21 & Poesía & 43 \\
\hline XVI & 6 & Religiosa & 17 & Prosa & 17 \\
\hline XVII & 6 & Costumbrista & 8 & Teatro & 3 \\
\hline XIX-XX & 5 & Moralista & 4 & Varia & 1 \\
\hline XVI-XVII & 5 & Amorosa & 4 & & \\
\hline XVIII-Xix & 3 & Varia & 3 & & \\
\hline Varia & 2 & Religiosa-moralista & 2 & & \\
\hline XIII & 2 & Bucólica & 2 & & \\
\hline $\mathrm{XV}$ & 2 & Religiosa-amorosa & 1 & & \\
\hline s.f. & 1 & Mitológica & 1 & & \\
\hline XV-XVI & 1 & Religiosa-folklore & 1 & & \\
\hline
\end{tabular}

A la vista de estos resultados se puede afirmar que el canon literario que emplea Blanco en su Tratado podría calificarse de clásico, conservador y de temática claramente religiosa o generalista (naif en muchos casos), con 
especial atención a los autores del Siglo de Oro, como representantes de la literatura (texto literario escrito) en la época de mayor esplendor de las letras hispánicas. Así, los autores predilectos por Blanco son Cervantes, fray Luis de Granada, Berceo, Zorrilla, fray Luis de León, Quintana, Lope de Vega, Quevedo, Núñez de Arte y sor Juana Inés de la Cruz. Destacan los autores áureos y los autores de temática mística o ascética (religiosa en sentido amplio). La temática de los textos seleccionados, por Blanco, de estos autores es, además, no transgresora, pues se muestran poemas (el género poético es el predilecto de Blanco) de tema generalista y que hemos tildado de naif (composiciones dedicadas a las flores, la música, el amor ingenuo, etc.). El anti-canon que Quijada van den Berghe (2012) señala para el XVII, XviII y principios del xix es desoído en los inicios del siglo $\mathrm{xx}$, donde se retoma la herencia clásica de los poetas (continúa, en ese mismo sentido, el anti-canon de los dramaturgos y, en menor medida, de los prosistas) y se afianza una predilección por la literatura romántica y costumbrista del xix, seña de identidad en el nivel extralingüístico de la ideología de Blanco y Sánchez.

Estas conclusiones generales se corroboran empíricamente si analizamos las ocurrencias de canon de la tabla 3:

a) Con relación a la centuria o época de la literatura preferidas por Blanco, se constata la atención en un 45,6\% a autores del xix (en un sentido amplio: desde finales del xvin hasta principios del xx); y en un $39,1 \%$ para autores áureos.

b) En cuanto a la temática de los textos canónicos, sobresalen, con un $39,06 \%$, los contenidos religiosos o moralistas (conservadores), con variedades mixtas de poemas o composiciones de corte religioso-moralista, religiosoamoroso o religioso-folklórico. La elección de temas ingenuos o triviales (temática naif) se refleja en un 32,8\% de los textos. La atención al folklore y a las costumbres es una manera de asentar una ideología casticista, nacionalista y tópicamente hispánica, una forma de acercar al alumnado la idiosincrasia conservadora y, en cierto sentido, un cliché o estereotipo de la España de principios del siglo xx.

c) Por lo que respecta al género literario, la poesía ocupa el $67,1 \%$, frente a la prosa que obtiene un $26,5 \%$ del total de ocurrencias, en tanto que el teatro se sitúa en un insignificante $4,6 \%$. La tradición clásica y poética es, sin duda, la preferida por Blanco en su canon literario.

d) Conviene hacer notar, como ya se ha indicado, la presencia notable de místicos, ascetas, sacerdotes o autores proclives a la temática religiosa. Este canon predilecto se une a la presencia de un 10,8\% de mujeres autoras, algo, sin embargo, poco común entre los gramáticos de esta época: sor Juana Inés de la Cruz, Cecilia Böhl de Faber, Concepción Saiz, Blanca de 
los Ríos Lampérez y santa Teresa de Jesús. Contrasta la presencia de santas o religiosas (aunque transgresoras en muchos sentidos) junto a Blanca de los Ríos (destacada intelectual, defensora de la mujer y de las relaciones entre España y Latinoamérica) o Concepción Saiz Otero, reputada pedagoga y comprometida con el movimiento feminista y la igualdad entre mujeres y hombres. Este hecho pone de relieve la ideología conservadora de Blanco unida a un pensamiento culto y, en cierta forma (no solo en materia gramatical), aperturista para los autores que integraban el bloque de gramáticos o intelectuales de la llamada pedagogía católica.

\section{Síntesis, Resultados y CONClusiones}

Con esta investigación hemos pretendido el análisis de las relaciones entre ideología y gramática en el Tratado elemental de la lengua castellana (1915) de Rufino Blanco y Sánchez (1861-1936) a través de marcas concretas en los microtextos de los ejemplos y los ejercicios. Para este fin, hemos articulado el estudio a partir de la concepción de la ideología como índices o marcas de pensamiento compartido (en la línea de Van Dijk, 1998) o de creencias diversas, que en el caso de la gramática se concretan en dos niveles; uno, intralingüístico, que hace referencia a representaciones teóricas o de programa científico; otro, extralingüístico, que guarda relación con creencias o representaciones de índole social, política, filosófica, religiosa, histórica o cultural. Este segundo nivel ha sido el objeto específico de nuestra investigación en este trabajo.

Metodológicamente, hemos adoptado la perspectiva mixta de historiografía lingüística interna y externa (Swiggers, 1980; Brekle, 1986) y la interpretación del hecho historiográfico como un acto comunicativo (Zamorano Aguilar, 2010). En concreto, de la aplicación de la teoría comunicativa al discurso gramatical empleado por Blanco en su Tratado podemos extraer las siguientes conclusiones sobre la ideología en el nivel extralingüístico:

1. Con relación al contexto, nos encontramos en el reinado de Alfonso XIII, caracterizado por el esplendor artístico y literario, la pugna entre conservadores y liberales y su turnismo político (Seco Serrano, 1992), así como la tensión entre pedagogía humanista católica y pedagogía reformista o liberal (Delgado Criado, 1994; Zamorano Aguilar, 2013). Hemos podido comprobar cómo el Tratado de Blanco contiene numerosas marcas/índices de esa ideología mixta, fiel al ambiente socio-político de la época, marcado por su conservadurismo e institucionalismo.

2. Por lo que respecta al emisor, Rufino Blanco y Sánchez, fue un profesor e intelectual español, heredero del historicismo pidaliano y apegado a la filología tradicional. Encarnaba, junto a otros pedagogos de la época, la 
vertiente cristiano-católica y conservadora de la didáctica española a principios del siglo xx. Pero se trataba también de un tratadista culto y atento a los nuevos vientos científicos en materia lingüística, lo que le lleva a mostrarse innovador en materia teórica, aunque en el nivel extralingüístico de su ideología ese aperturismo resulta bastante escaso.

3. En cuanto al receptor, el Tratado de 1915 está destinado al alumnado de bachillerato y de las Escuelas Normales, uno de los focos de interés editorial de Blanco. Su obra fue no solo bien recibida sino prestigiada (consciente o inconscientemente) si tenemos en cuenta los galardones que recibió y el favor de la institución académica. Este hecho justifica, socialmente, el carácter poco transgresor de su ideología en materia socio-política y cultural.

4. El Tratado de 1915 es un canal (texto gramatical) de corte pedagógico-didáctico. Este formato permite el desarrollo de ideología teórica y socio-histórico-cultural en los dos niveles descritos. De hecho, los paratextos (portada y prólogo) muestran también notables índices de la ideología del autor en su nivel extralingüístico: la literatura con fin didáctico y doctrinal, el costumbrismo del recurso frecuente a las paremias, la atención a la historia del español, el enfoque filológico y tradicional y la defensa del patrimonio literario y cultural de España son muestras palmarias de su pensamiento socio-político-cultural y pedagógico.

5. El debate sobre la nomenclatura del código es fiel al ambiente de principios del siglo xx. La terminología de la lengua es una marca evidente de la tensión entre innovación/tradición que hemos observado en otros ejes del proceso comunicativo gramatical de Blanco. Defiende, en su Tratado, de forma conservadora y academicista el rótulo de castellana, aunque también emplea (sin justificación técnica explícita) la denominación de española, que no será utilizada por la RAE hasta 1924.

6. Finalmente, el mensaje de Blanco, esto es, el discurso gramatical, se puede concretar en los dos niveles ideológicos ya expuestos: (a) nivel intralingüístico (que fue objeto de estudio en Zamorano Aguilar, 2019); (b) nivel extralingüístico, que se concreta en el canon literario (tanto en ejemplos como en lecturas), los ejemplos, los ejercicios, las explicaciones y los temas para la composición. Este nivel ha permitido demostrar la formalización de la ideología socio-histórico-cultural.

Así, el análisis de los fragmentos textuales (ejemplos, ejercicios, etc.) y el canon literario ha puesto de manifiesto una ideología que, en contraste con la tensión conservadurismo/aperturismo de la ideología teórica, se muestra claramente conservadora, moralista, de corte religioso-católico, con sutiles vías de modernidad, mínimas muestras que lo singularizan dentro de la pedagogía humanista católica. El canon literario que emplea Blanco puede calificarse de clásico, tradicional y claramente atento a una temática religiosa 
o generalista (naif en muchos casos). Destacan los autores del Siglo de Oro y los místicos-ascetas (incluso en la ideología teórica sobresalen gramáticos o intelectuales sacerdotes también) y del siglo xix, se apuesta por el texto escrito (en las lecturas) y por el ejemplo inventado (en la mayoría de los casos) para los ejemplos y los ejercicios, con una apuesta por el género poético, por el folklore y la tradición.

Por último, conviene destacar los cuatro ejes/criterios (inversamente proporcionales) de la relación entre los niveles intra y extralingüísticos de la ideología en Blanco, con el fin de observar el peso de la ideología sociohistórico-cultural en el programa pedagógico y gramatical de nuestro tratadista a través de los ejemplos y ejercicios:

a) La presencia de ejemplos meta (metaconocimiento lingüístico, literario, etc.) supone la potenciación del nivel intra de la ideología, frente a una neutralización de los valores extra.

b) El empleo de ejemplos inventados permite potenciar los contenidos teóricos (nivel intra) y, en consecuencia, se ve debilitado el nivel extralingüístico.

c) La elección de ejemplos de temática naif, según nuestra denominación, supone en Blanco potenciar o focalizar, didácticamente, los contenidos teóricos objeto de explicación y, por el contrario, desviar la atención de los aspectos de tipo socio-histórico-cultural (nivel extralingüístico).

d) Por último, el recurso a fragmentos o citas literarias (en un sentido amplio), es decir, ejemplos extraídos de autoridades textuales y, por tanto, ejemplos no inventados, ha privilegiado en Blanco la presencia (subliminal o no) de aspectos extralingüísticos, en detrimento de los contenidos teóricos que en esos casos concretos se abordan.

En definitiva, hemos intentado mostrar cómo la ideología (en su vertiente teórica y, específicamente, socio-histórico-cultural) encuentra en la obra gramatical (y, en concreto, en los microtextos de los ejemplos) un canal idóneo para que el emisor (en este caso Blanco) brinde a sus receptores (bachilleres y estudiantes de las Escuelas Normales) una visión del mundo y de la gramática que resulta ser espejo fiel de las tensiones y del ambiente cultural, social y político-ideológico de la España de principios del siglo pasado. El texto gramatical, lejos de ser un objeto ajeno a su entorno extralingüístico, se presenta como un canal excelente de concreción de ideologías de naturaleza diversa.

\section{Bibliografía}

BREKLE, H.E. (1986): «What is History of Linguistics and to what end is it produced? A didactic approach». En Bynon, T. y Palmer, F.R. (ed.): Studies in the history of Western Linguistics: in honour of R.H. Robins. Cambridge, CuP, págs. 1-10. 
Calero Vaquera, M.L. (2004): «Métodos de enseñanza gramatical en la tradición: propuesta de nueva disciplina». En Corrales, C. et al. (eds.): Nuevas aportaciones a la historiografía lingüistica (Actas del IV Congreso Internacional de la SEHL). Madrid, Arco/Libros, vol. 1, págs. 317-326.

- (2010): «Ideología y discurso lingüístico: la Etnortografía como subdisciplina de la glotopolítica». Boletín de Filología, 45.2, págs. 31-48.

Cappeau, P. et al. (dir.) (2010): L'exemple et le corpus: quel statut? Rennes, Presses Universitaires de Rennes.

Cardona, G.R. (1976): Introduzione all'etnolinguistica. Bologna, Il Mulino.

Casado Velarde, M. (1991): Lenguaje y cultura. Madrid, Síntesis.

Chevalier, J.C. (1976): «Le jeu des exemples dans la théorie». En Chevalier, J.C. et al.: Grammaire transformationnelle: syntaxe et lexique. Lille, Presses Universitaires de Lille, págs. 233-263.

Chevillard, J.L. et al. (2007): «L'exemple dans quelques traditions grammaticales (formes, fonctionnement, types)». Langages, 166.2, págs. 5-31 (en línea: <https:// www.cairn.info/revue-langages-2007-2-page-5.htm> [consulta: 20 de noviembre de 2018]).

Chierchietti, L. (2010): «Los ejemplos en las dos primeras gramáticas de español para italianos: algunas consideraciones sobre las fuentes literarias». Culture et Histoire dans l'Espace Roman, 5, págs. 47-62.

Coseriu, E. (1981): «La socio- y la etnolingüística: sus fundamentos y sus tareas». Anuario de Letras, 19, págs. 5-29.

De Kоск, J. (1990): «A propósito de los ejemplos en la gramática (La concordancia entre el verbo y su regente)». En De Kock, J. (coord.): Gramática española. Enseñanza e investigación. Apuntes metodológicos. Salamanca, Universidad de Salamanca, págs. 41-52.

Delgado Criado, B. (coord.) (1994): Historia de la educación en España y América. Madrid, Ediciones SM.

Duranti, A. (2000): Antropología lingüistica. Madrid, Cambridge University Press.

ENFIELD, N.J. (2002): Ethnosyntax: Explorations in Grammar and Culture. Oxford: Oxford University Press.

Escudero Paniagua, F. (2017): «Los ejemplos empleados para diferenciar el pasado simple del compuesto (1769-1854). Tipos, funciones, fuentes y contextualización». Orillas, 6, págs. 571-595.

Esteba Ramos, D. (2005): Los ejemplos en las gramáticas del español como lengua extranjera: Siglo de Oro. Tesis doctoral. Málaga, Universidad de Málaga (en línea: <http:// hdl.handle.net/10630/2728> [consulta: 20 de noviembre de 2018]).

Fournier, J.M. (1998): «À propos des grammaires françaises des XVII ${ }^{\mathrm{e}}$ et XVIII ${ }^{\mathrm{e}}$ siècles: le traitement des exemples et des parties du discours». Histoire, Épistémologie, Langage, 20.2, págs. 127-142.

Gómez Asencio, J.J. (2016): «Del valor de las autoridades y de sus muestras de lengua (en la gramática tradicional española)». La torre di Babele. Rivista di letteratura e lingüistica, 12 [Discorso e oralità], págs. 145-167. 
Jakobson, R. (1983): Lingüística y poética. F. Abad (estudio preliminar) y A.M. Gutiérrez Cabello (trad.). Madrid, Cátedra.

Kistereva, M. (2014-2015): L'exemple dans les grammaires de l'Europe occidentale des XV et XVI siècles. Tesis doctoral. Bruxelles, Université Libre de Bruxelles.

Lliteras Poncel, M. (2001): «Sobre la formación del corpus de autoridades en la gramática española». En Koerner, E.F.K. y Niederehe, H.J. (eds.): SHLS 2001. History of Linguistics in Spain II. Amsterdam, John Benjamins, págs. 215-228.

NARvaja, E. (2008): Los discursos sobre la nación y el lenguaje en la formación del Estado (Chile, 1842-1862). Estudio glotopolítico. Buenos Aires, Santiago Arcos Editor.

Niederehe, H.J. (1994): «Los ejemplos de la Gramática de la lengua castellana de Elio Antonio de Nebrija». En Escavy, R. et al. (eds.): Nebrija v Centenario: Actas del congreso internacional de historiografía lingüistica. Murcia, Universidad de Murcia, vol. 1, págs. 413-435.

Olкhovikov, B. (1985): Teorija jazyka $i$ vid grammaticheskogo opisanija $v$ istorii jazykoznanija. Moscú, Nauka.

Quijada van den Berghe, C. (2008): «Pautas para el estudio de las autoridades y el canon en las gramáticas del español del siglo xviI». En Gómez Asencio, J.J. (dir.): El castellano y su codificación gramatical. De 1614 (B. Jiménez Patón) a 1697 (F. Sobrino). Burgos, Fundación Instituto Castellano y Leonés de la Lengua, vol. 2, págs. 641-666.

- (2012): «Autores malditos: el anti-canon literario en la historia de la gramática española». En Battaner Moro, E. et al. (eds.): Historiografía lingüistica: líneas actuales de investigación. Münster, Nodus Publikationen, págs. 711-725.

- (2017): La parfaicte méthode pour entendre, escrire, et parler la langue espagnole de Charpentier (1596). Edición facsimilar, transcripción, traducción y estudio. Salamanca, Universidad de Salamanca.

Seco Serrano, C. (1992): Alfonso XIII y la crisis de la restauración. Madrid, Ediciones Rialp. Swiggers, P. (1980): «The Historiography of Linguistics». Linguistics, 18, págs. 703-720.

Terracini, B. (1951): Conflictos entre lenguaje y cultura. Buenos Aires, Ediciones Imán. VAN Dijk, T.A. (1998): Ideología: un enfoque interdisciplinario. Barcelona, Gedisa.

Wierzbicka, A. (1979): «Ethno-syntax and the Philosophy of Grammar». Studies in Language, 3.3, págs. 313-383.

Wooldrigde, R. (1995): «Naissance et première floraison de l'example dans la lexicographie française». Langue française, 106, págs. 8-20.

Zamorano Aguilar, A. (2010): «Teoría del canon y gramaticografía. La tradición española de 1750 a 1850». En Gaviño, V. y Durán, F. (eds.): Gramática, canon e historia literaria (1750 y 1850). Madrid, Visor Libros, págs. 421-466.

- (2012): «Teorías del caos e historiografía de la lingüística. Una interpretación». Beiträge zur Geschichte der Sprachwissenschaft, 22.2, págs. 243-298.

- (2013): «La investigación con series textuales en historiografía de la lingüística. A propósito de la obra de F. Gámez Marín (1868-1932)». Revista Internacional de Lingüistica Iberoamericana, 21.1, págs. 173-192. 
- (2017): «Series textuales, edición de textos y gramaticografía. Teoría, aplicación, constantes y variables». Beiträge zur Geschichte der Sprachwissenschaft, 27.1, págs. 115-135.

- (2019): «La obra gramatical como fuente de ideologías en historiografía de la lingüística: El nivel intralingüístico». Tonos Digital, 36, págs. 1-23 (en línea: <http://www.tonosdigital. es/ojs/index.php/tonos/article/view/2130> [consulta: 25 de junio de 2019]). 